\title{
Saúde Perinatal em Ribeirão Preto, SP, Brasil: A Questão do Método *
}

\author{
Marco A.Barbieri ** \\ Uilho A. Gomes \\ Antônio A. Barros Filho **** \\ Heloisa Bettiol ** \\ Luis Eduardo A. Almeida ** \\ Antonio Augusto Moura da Silva ***
}

* Este estudo contou com o apoio do Centro de Amparo ao Estudo e Pesquisa em Pediatria Social (CAEPPS) e da Fundaçâo de Amparo à Pesquisa do Estado de São Paulo (F APESP).

* Universidade de Sâo Paulo. Departamento de Puericultura e Pediatria da Faculdade de Medicina de Ribeirão Preto

** Universidade de São Paulo, Departamento de Medicina Social da Faculdade de Medicina de Ribeirão Preto.

**** Universidade de Campinas, Departamento de Pediatria da Faculdade de Ciéncias Médicas.
Os autores apresentam a metodologia do planejamento, montagem, execução empírica e um protótipo de análise de pesquisa em saúde perinatal. No projeto foram estudados todos os partos hospitalares (resultando recém-nascidos vivos) no município de Ribeirão Preto, Brasil, no período de 1 de junho de 1978 a 31 de maio de 1979. O estudo foi feito através de entrevistas com todas as puérperas que deram i luz nos 8 hospitais-maternidades do município, e as informaçōes obtidas referiam-se aos pais, à renda, à gestação e ao parto, incluindo a atenção médica ao recém-nascido, ao óbito da criança (quando ocorresse), à etnia e à reprodução humana. São apresentados em detalhes, os passos para a execuçāo do projeto, bem como a conceituaçāo da classe social e sua operacionalizaçāo, ponto básico para o modelo de análise.

\section{INTRODUÇÃO}

$\mathrm{Na}$ fase atual da vida social brasileira existem obstáculos para a criação de um sistema eficaz de proteçāo e promoção da saúde, mas também um promissor despertar da consciência popular em torno do assunto.

A vida, a saúde e o bem-estar material e espiritual sāo requisitos elementares da condiçāo humana, e a carência de qualquer desses requisitos suprime ou, pelo menos, prejudica essa condição genuinamente humana do ser. O direito de todas as crianças à vida, à saúde, ao bem-estar e a uma formação integral está estreitamente vinculado às condições gerais econômicas, sociais e legais imperantes na sociedade (1).

Desde o aparecimento da vida sobre a terra, a doença a ela esteve associada, portanto antiga como a própria vida, porque é um atributo da vida. Como fenômeno biológico, as causas da doença estão enraizaCadernos de Saúde Pública, RJ, 5 (4): 376-387, out/dez, 1989. 
das no reino da natureza, mas no homem a doença possui uma outra dimensão: nele a doença não existe como "natureza pura", sendo mediada e modificada pela atividade social e pelo ambiente cultural que tal atividade cria. Mas só nos tempos modemos aparece uma consciência clara quanto à íntima articulação das condiçóes sociais e dos problemas médicos (2).

Portanto, a saúde da populaçáo e, conseqüentemente, a do indivíduo não pode, como tem ocorrido, ser considerada isoladamente, alheia ao contexto social e econômico pois, na prática, as oportunidades e o "modo de andar a vida" de um grupo ou sociedade estão incluídos dentro das relaçōes sociais de produção e do próprio modo de produção que lhe dá determinaçāo histórica.

Numa sociedade que não é somente estratificada mas hierarquizada, o que domina todas as relações de classes é uma relação de desigualdade, e as diferenças entre as classes sociais são essencialmente vistas e/ou interpretadas como diferenças quantitativas exprimidas em temos de "mais ou menos" (3). Assim, por exemplo, as proporçōes de recém-nascidos de baixo peso, os coeficientes de mortalidade neonatal ou in fantil para uma classe social podem demonstrar a maior ou menor probabilidade de morbi-mortalidade para uma criança nesta ciasse e em relação a outro grupo social.

Ás novas abordagens que vêm sendo desenvolvidas na epidemiologia, por entenderem que "os diferenciais de saúde e doença por classe social são os fundamentais em qualquer sociedade classista e os primeiros a investigar, coisa que quase nunca se tem feito" (4), apontam a possibilidade de se superar a simples constatação e descrição das desigualdades sociais no processo saúde-doença e no uso de serviços médicos, ao mesmo tempo que possibilitam a rediscussão destes dados em termos de modelos explicativos mais conseqüentes (5).

A utilização deste tipo de arcabouço no contexto da saúde adquire particular relevância para a compreensão dos processos que se colocam em jogo na decisāo de sima política de saúde e de recursos para a investigaçào nessa área, pois o grupo materno-infantil tem sido objeto de prioridade dos organismos de saúde, principalmente na América Latina, o mesmo ocorrendo no Brasil, onde representa parcela ponderável da população e tem conotaçōes específicas que respondem fundamentalmente por suas características biológicas e sociais $(6,7)$.

Numerosos estudos, na área matermo-infantil, têm mostrado a relação entre processo saúde-doença e variáveis como renda, escolaridade, saneamento, nutrição, atenção médica etc, e a estreita correlação que estes fatores apresentam entre si. Entretanto a distriCadernos de Saide Pública, RJ, 5 (4): 376-387, out/dez, 1989. 
buição desigual dos mesmos na população são a expressão visível (valores medidos) de uma cadeia causal que se estabelece na organizaçáo social, econômicr. e política de uma sociedade (8).

Estudos epidemiológicos sobre problemas de saúde perinatal têm sido motivo freqüente de publicaçōes, principalmente nas questōes ligadas a nutriçāo materna, desenvol vimento fetal e baixo peso ao nascer, com suas implicaçōes imediatas e tardias $(9,10,11,12)$. Alguns autores defendem a idéia que, para se ter bons níveis de saúde perinatal, necessita-se de uma adequada estrutura sócio-econômica e um eficiente e eqüitativo sistema de saúde $(13,14)$.

Ao se estudar o processo saúde-doença, o período perinatal representa uma situaçāo muito particular para se conhecer o efeito da situação sócio-econômica de um grupo ou classe social sobre a sobrevivência e o desenvolvimento humano. Um vasto corpo de informaçōes acumuladas nestas últimas 3 décadas indica que uma excessiva morbi-mortalidade perinatal é o resultado de grandes privações sócio-econômicas. Evidências sugerem que dois dos mais importantes mecanismos que podem prejudicar o desenvolvimento e a sobrevivência do feto são a desnutrição matema e seu meio ambiente desfavorável e que podem ser agravados por uma decisiva falta de acesso e distribuição efetiva e eqüitativa de serviços de saúde (15). Sua origem é, basicamente, provocada pelo modo de produção dominante que cria diferentes classes sociais que vão ocupar posiçōes distintas e antagônicas nas relações sociais de produção.

Enquanto uma série de variáveis tidas como de ordem biológica tem sido objeto de estudos com critérios bem precisos, ao se tratar dos aspectos sociais envolvidos no conjunto da saúde perinatal, observa-se uma realidade diversa. Assim, o conjunto de fatores conhecidos sob o nome de "nível sócio-econômico tem sido trabalhado de maneira heterogênea e ao critério individual de cada investigador". Entretanto, será possível interpretar e conhecer, por exemplo, o fenômeno do baixo peso ao nascer e suas relaçōes causais através do estudo dos fatores de risco, considerados de forma isolada ou mediante sua reuniăo em fómulas matemáticas? Será possível compreender o processo saúdedoença "biologizando" o social? (16)

Neste processo, como refere BEHM (8), se reconhece profundamente a existência de determinantes biológicos no processo saúde-doença. O que se pretende é tentar articular o biológico em um contexto social, na tese de que as causas sociais podem desencadear e transformar os fatores biológicos. Assim, por exemplo, a maior mortalidade infantil ou maior proporção

Cadernos de Saúde Pública, RJ, 5 (4): 376-387, out/dez, 1989. 
de baixo peso nos filhos de mulheres nas idades extremas e o maior risco nos recém-nascidos de grandes multíparas podem ter uma explicação biológica. Mas, por sua vez, são determinantes sociais do comportamento reprodutivo (fecundidade), condicionando que as mulheres dos grupos sócio-econômicos baixos tenham uma reprodução de início precoce, elevada e prolongada, com maior proporção de nascimentos nos grupos de maior risco. A importância relativa dos fatores biológicos e sociais dependerá da etapa histórica em que cada formação social se encontre, assim como - nível e o perfil da morbi-mortalidade que resulta dela.

Em razão desta noção foi desenvolvido um projeto epidemiológico na área matemo-infantil diretamente equacionado na comunidade, a fim de se dispor de um grande campo de investivação das questōes perinatais e de reproduçāo humana, para análise do processo saúde-doença e da assistência médica e suas conseqüências na mortalidade infantil e nas outras épocas da vida.

Assim, a presente publicação foi elaborada com - objetivo de descrever o planejamento, montagem e execução empírica e um protótipo de análise de pes. quisa em saúde perinatal.

\section{METODOLOGIA DA INVESTIGAÇĀO EMPIRICA}

\section{Características da população geral}

Ribeirão Preto, cidade situada $320 \mathrm{~km}$ a nordeste da capital do Estado de São Paulo - São Paulo na Região Sudeste do Brasil, contava na Época do levantamento $\operatorname{com} 318.496$ habitantes no município, distribuídos numa área de $1057 \mathrm{~km} 2$ (densidade demografica de $301,21 \mathrm{hab} / \mathrm{km} 2$ ). Destes, 308.345 habitantes $(96,81 \%)$ residiam na zona urbana e 10.151 $(3,18 \%)$ na zona rural. Havia 77.105 domicilios particulares e fixos, dos quais $81,26 \%$ eram ligados à rede de esgotos e $98,13 \%$ tinham luz elétrica (17).

A população economicamente ativa (PEA) correspondia a 136.034 indivíduos $(42,71 \%$ da população total), e as principais atividades econômicas eram prestação de serviços, comércio de mercadorias e indústria de transformaçáo - destacando-se a agroindústria da cana-de-açúcar, sendo a regiāo a mais importante do país nessa atividade - que absorviam 77.399 pssoas (56,89\% da PEA).

O rendimento mensal médio per capita era de 1 ,85 salários mínimos (salário mínimo em maio de 78: 1.560 cruzeiros, dólar em junho de 78: 18,00 cruzeiros e maio de 79: 25,60 cruzeiros), sendo que 
35.676 indivíduos $(26,22 \%$ da PEA) percebiam até 1 salário mínimo e 25.801 (18,96\% da PEA) acima de dez.

Com relação à escolaridade estimava-se que 244.937 pessoas a partir do 5 : ano de vida $(86,14 \%$ da populaçāo total nessa faixa etária) eram alfabetizados.

Ribeirāo Preto contava, na época, com 8 hospitais que apresentavam serviço de matemidade: um hospital universitário (Hospital das Clínicas - HC) que atendia quase que exclusivamente indigentes, composto de duas unidades ("Cidade e Campus"), um outro que atendia indigentes, previdenciários e particulares (Santa Casa de Misericórdia - HSC), quatro que atendiam previdenciários e particulares (Hospital São Francisco - HSF, Hospital Ribeirânia - HR, Hospital Beneficência Portuguêsa - HBP e Hospital São Paulo HSP) e um que atendia prioritariamente particulares (Hospital São Lucas - HSL). Em Ribeirão Preto o atendimento hospitalar aos previdenciários tem sido feito por hospitais privados conveniados com o INAMPS (Instituto Nacional de Assistência Médica da Previdência Social). Em alguns casos os honorários médico-hospitalares têm sido complementados pelo usuário (INAMPS mais complemento). Em outros casos, tanto a assistência pré-natal quanto hospitalar vêm sendo feitas por outros convênios, como Cruz A zul, convênio com empresas, com o serviço público municipal e estadual, etc.

\section{A população de estudo}

A decisão quanto à população de estudo baseou-se no fato de vários trabalhos terem demonstrado que, em Ribeirāo Preto, a maioria dos nascimentos ocorrem em hospitais. Já em 1956 essa freqüência é relatada como $71,3 \%$ passando a $83 \%$ em 1962 (18) e atingindo o valor de 93,4\% em 1966 (19). Em 1971, Teruel (20) reafirma esses valores que coincidem com os achados da "Investigaçâo Interamericana de Mortalidade na Infância" (21), on de verificou-se entre 1968 e 1970 a proporção de $95 \%$ dos nascimentos como hospitalares e, finalmente, Carvalheiro (22) refere que esses valores em 1972 e 1974 correspondem a mais de $95 \%$.

As informaçōes que compōem basicamente todo - projeto desta investigaçāo estāo contidas nos 9266 questionários que representam, aproximadamente, 98\% do universo de partos de crianças nascidas vivas (número de nascidos vivos) nas 8 maternidades dos hospitais de Ribeiräo Preto durante o período de um ano. Destes nascimentos, $7023(75,8 \%)$ foram de residentes no município de Ribeirăo Preto, o que repre- 
sentou aproximadamente $95 \%$ do universo de nascidos vivos no ano de 1979 que, segundo o IBGE (17), foi de 7437 crianças. A periodicidade escolhida para o levantamento - 01 de junho de 1978 a 31 de maio de 1979 - relaciona-se com a época de modificação do salário mínimo, que permanecia constante por um ano, sendo reajustado anualmente no mês de maio.

Os questionários especialmente preparados para o projeto constaram fundamentalmente de 8 itens principais relativos aos pais, à renda, à gestação e ao parto, incluindo a atenção médica, ao recém-nascido, ao óbito da criança (quando ocorresse), à etnia e à reprodução humana. $(23,24)$

As informaçōes foram obtidas através:

- de entrevistas com as mães que deram à luz um ou mais nativivos (um questionário para cada nascido vivo); nidades;

- do registro e prontuários dos hospitais-mater-

- dos valores antropométricos dos recém-nascidos (peso, comprimento, comprimento tronco-cefálico e perímetro craniano) colhidos entre 12 a $24 \mathrm{~h}$ de vida somente nas duas unidades do $\mathrm{HC}$ e no JSF, além do peso e comprimento ao nascer de todas as crianças do projeto (25);

-- dos mapas demógrafo-sanitários do Departamento Region?" de Saúde (DRS-6) e dos atestados de óbito das crianças do projeto que morreram durante o primeirn ano de vida, colhidos nos cartórios de Ribeirāo Pretr s seus distritos.

\section{Trabalho de campo e sua operacionalidade}

O preenchimerto dos questionários pode ser dividido em duas fases:

\section{a) Visitas aos Hospitais}

Durante o período de estudos as entrevistadoras e as técricas em antropometria, diariamente, visitavam todas as matemidades e colhiam as informaçōes para preenchimento do formulário. A entrevista foi sempre realizada após o parto, e a cada uma das mães era explicado o objetivo da mesma e solicitada sua colaboração. Se estivesse de acordo, a entrevista era realizada segundo o manual de instruçōes e a seguir era completada com os dados de informaçōes hospitalares. Nos casos em que a mãe recebesse alta hospitalar antes da entrevista, esta era realizada no seu domicílio até - 15 dias após o parto desde que residisse na zona urbana de Ribeirão Preto e, em caso de residir na zona rural ou em outro município, a entrevista ficava incompleta. 
A fim de evitar a exclusão de pacientes, diariamente era efetuada uma listagem de todas aquelas intermadas em trabalho de parto, em todos os hospitais, sendo depois feita a conferéncia com as fichas de entrevistas. Além disso, havia uma reuniáo semanal com todo o grupo participante da in vestigaçāo, a fim de permitir a discussão e resolução rápida de problemas ocorridos.

b) Levantamento dos óbitos

Como o projeto se propôs a analisar a mortalidade infantil, foi necessário que o levantamento dos óbitos das crianças incluídas no estudo se fizesse até um ano após o encerramento da coleta dos dados de nascimentos, isto $E$, até 31 de maio de 1980. (26)

Para que isso fosse possível, o elemento responsável pelo registro dos óbitos utilizou várias fontes de informaçōes como os mapas demógrafo-sanitários da DRS 6 e os próprios dos hospitais, mas o principal foi o levantamento de dados dos livros de óbitos de todos os cartórios do município de Ribeiráa. Preto. Selecionados e copiados todos os atestados de óbitos das crianças menores de um ano, os pertencentes ao projeto foram anexados aos respectivos questionários. Além disso, foi necessário recorrer aos atestados de natimorte, onde foram localizados alguns casos de mortes no primeiro dia que constaram do levantamento hospitalar feito pela equipe (26) que, assim, não constavam das informaçōes hospitalares.

\section{Pessogl envolvido na investigaçāo e seu treinamento}

A coordenaçáo geral ficou com dois docentes do Departamento de Pediatria e um docente do Departamento de Medicina Social da Faculdade de Medicina de Ribeirio Preto. Estes já haviam, em outras oportunidades, participado como membros de equipe ou coordenando outros projetos dessa natureza $(21,27,28$, 29).

Durante a fase de treinamento da equipe de entrevistadores foi aplicado um questionário em 450 puérperas em 3 hospitais-matemidades (projeto-piloto), com - objetivo de criar condiçōes de padronizaçáo das entrevistas e identificaçáo de possiveis defeitos do questionário. A mesma precauçấo foi tomada em relaçâo às medidas antropométricas. O controle da distribuiçấo, recebimento e correçāo do preenchimento e ordenaçáo do material para codificação ficou a cargo de uma secretária.

A equipe de campo foi composta por 5 entrevistadoras previamente treinadas pelos coordenadores e uma 
assistente social com experiência anterior em projeto de investigação por entrevista domiciliar (30). A parte de antropometria foi realizada por 2 técnicas em medidas previamente padronizadas. Finalmente, a parte do levantamento dos atestados de óbito nos cartórios e dos casos que, por questões éticas, não foram entrevistados ficou sob a responsabilidade de um pós-graduan do de Pediatria.

\section{Condições para realização do projeto}

Para que o estudo pudesse ser desenvolvido a contento, foi obtida permissão de todos os diretores clínicos dos hospitais-matemidades, dos cartórios de registros e do DRS-6, visando o acesso da equipe aos respectivos serviços.

$\mathrm{Na}$ fase preparatória do projeto,em todos os hospitais,o pessoal paramédico encarregado de pesar e medir o comprimento dos recém-nascidos foi testado para se estimar a confiabilidade dos valores. Do mesmo modo, as balanças foram testadas e calibradas (se necessário substituídas por nova. Foram construídas craveiras especiais para medir recém-nascidos e doadas a todos os serviços envolvidos no projeto.

Finalmente, as questōes éticas foram discutidas com docentes da Medicina Legal, quando então se fixarom as diretrizes de que não seriam entrevistadas aquelas mães que:

- não dessem seu consentimento, ou que seu médico não permitisse; saúde;

- nâo estivessem em condiçōes satisfatórias de

- seus filhos nascessem mal ou tivessem falecido.

Decidiu-se também que não seriam incluídos os casos de mães que falecessem no parto e as que dessem luz natimortos.

\section{Processamento de dados}

Uma vez completo, o questionário era revisado pela secretária e por um dos coordenadores e, a seguir, uma equipe composta de 3 pós-graduandos de Pediatria e 1 enfermeira procediam à codificação do material, utilizando-se de um manual específico. Após a codificação, os dados foram transferidos para cartóes IBM e fita magnética, para posterior processamento em computador eletrônico. 


\section{A questão da classe social: - conceituação e opera - cionaliz açāo}

Dentro da análise do modelo foi necessário primeiramente conceituar a questão da classe social e sua operacionalização, já que seria o ponto básico de sustentação de todo o projeto e da maioria dos subprojetos.

O conceito de classe social escolhido foi baseado no modelo proposto por SINGER (31) e adaptado para uso epidemiológico por BARROS (5) que considera que a determinação básica das classes sociais se dá ao nível das relações sociais de produção, e sua operacionalização emprega basicamente dois indicadores: "posição na ocupação " (rel ação de trabalho) e "tipo de ocupação" em relação a inserção do "chefe de família" no processo produtivo; por outro lado, "nível de renda" e "número de empregados" estabelecem com os outros indicadores um conjunto de grupos "sócio-ocupacionais", que, reagrupados, permitirão a discriminação das "frações de classe" na população estudada.

A utilização da classe social nos modelos epidemiológicos tem sido criticada por alguns sociólogos que perguntam sobre a validade do modelo para observação de casos individuais. Uma limitação desta caracterização é de que esta se restringe a captar a situação de classe através da estrutura econômica, portanto, a classe em si, não captando a posição de classe (dada pelo nível de percepção de renda, consumo) nem os valores, a ideologia, as posições políticas dos membros de cada classe, portanto não a fere a superestrutura, ou melhor, a classe para si. Outro ponto é que se percebe a realidade petrificada em um momento histórico, sincronicamente, não permitindo por exemplo o estabelecimento de relaçōes temporais entre sujeitoobjeto historicamente considerado (32). O modo de vida sendo determinado pelo processo de produção, por sua vez, exerce influência sobre o mesmo. No interior da classe social o modo de vida é heterogêneo, pois relaciona-se à vivência anterior dos diferentes grupos sociais que o compóem, pela permanência dos mesmos em áreas urbanas, pelo trabalho concreto que executam, pela sua qualificação e pelo montante dos salários (5). Assim, é com referência à posição de classe e variáveis ligadas a ela e às condiçōes gerais de existência que deveráo ser analisados os perfis diferenciais de alguns aspectos da saúde materno-infantil e de sua atenção médica, o que deverá pautar a principal linha do projeto. 
A metodologia aqui descrita refere-se a um amplo projeto em saúde coletiva na área matemo-infantil,inicialmente denominado "Estudo epidemiológico-social de parâmetros da saúde materno-infantil", permitindo assim o desen volvimento de alguns estudos específicos em saúde perinatal, saúde da mulher, mortalidade infantil e seus componentes, atenção médica na área materno-infantil, entre outros. Longe de esgotar o assunto, muitas questōes, dúvidas e proposiçōes que estão sendo levantadas nesses estudos seräo objeto de consideração e aprofundamento, dada a amplitude dos problemas.

Os procedimentos utilizados neste projeto também se propōem a servir de subsídio e orientaçāo para estudos semelhantes.

O projeto original ainda permite que essa coorte de crianças e suas famílias seja estudada sob os mais diversos aspectos do processo saúde-doença nas várias épocas da vida, como está sendo feito no presente "Estudo da coorte de escolares nascidos nos Hospitais de Ribeirão Preto entre junho de 1978 e maio de 1979" (título provisório).

The authors introduce the methodology of planning, empiric execution and a model of analysis in perinatal health. Live births from nosocomical deliveries was studied at Ribeirão Preto's neighborhood, Brazil, from June 1978 to May 1979. Parturient women from 8 maternities were interviewed and information was obtained regarding parents, family income, pregnancy, delivery (including medical care to newborn), children deaths, race and human reproduction. It is showed, in detail, the stages of project execution. The model of social class used and its operations research a basic point in the analysis.

\section{REFERÊNCIAS BIBLIOGRÁFICAS}

1. A CRIANÇA em Cuba: 20 anos de revolução. São Paulo, Centro Editorial Latino-Americano, 1980.

2. ROSEN, G. Da polftica médica à medicina social: ensaios a história da assistência médica. Rio de Janeiro, Graal, 1979. 401p. Biblioteca de Filos of ia e História das Ciências, 8.

Cadernos de Saúde Pública, RJ, 5 (4): 376-387, out/dez, 1989. 
3. BOLTANSKI, L. Prime éducation et morale de classe. Dijon - Quetingny, École des Hautes Edutes en Sciences Sociales, 1984. 152p. Cahiers du Centre de Sociologie Europénne.

4. LA URE LL, A. C. Introdução. In: TIMIO, M. Chses sociales $y$ enfermedad: introduoción a una epilemiologia diferencial. México, Nueva Imagem, 1981.

5. BARROS, M. B. A. Saúde e classe social: um estudo sobre morbidade e consurio de medicamentos. Ribeiräo Preto, Uniyersidade de São Paulo, 1983, 167p. Tese (Doutoramento).

6. DIAZ del CASTILHO, E. Perinatologia y subdesarrollo. Bol. Of. Sanit. Panam. OPS, 84: 427-40, 1978.

7. ORGANIZACION MUNDIAL DE LA SALUD. Nuevas tendenciais y métodos de asistencia maternoinfantil en los servicios de salud: sexto informe del Comité de Expertos de la OMS en salud de la madre y el niño. Genebra, OMS, 1976. 109p. Série de Informes Técnicos, 600.

8. BEHM, H. Determinantes económicas y sociales de la mortalidad en América Latina. Rev. Cub. Adm. Salud. 6: 1-30, 1980.

9. AEBI, H. \& WHITEHEAD, R. EDS, Matemal nut rition during pregnancy and lactation. Bern. Hans Huber, 1980. 354p. (Nestlé Foundation Publication Series).

10. BUTLER, N. R. \& A LBERMAN, E. D., eds. Perinatal problems. Edinburgh and London, E. \& S. Livingstone LTD. 1969.

11. DOBBING, J. ed. Matemal nut rition in pregnancy - eating for two? London, Academic Press, 1981.

12. LECHTIG, A. et allii. Low birth weight babies: world wide incidence, economic cost and program needs. In: ROOTH, G. \& ENGSTROM, L. Perinatal care in developing countries. Uppsala, Perinatal Research Laboratory, 1977. p. 17-31.

13. ALBERMAN, E. Prospects for better perinatal health. Lancet. 1: $189-92,1980$.

14. FARNOT, U; DUENAS, E.; RIVERON, R. Mortalidad p erinatal en Cuba. Rev. Cubana Obst. Ginecol., 2: 135-46, 1976.

15. PETROS -BARVAZIAN, A. \& BEHAR, M. Low birth - weight - a mayor global problem. In: STERRY, G. \& MELLANDER, L., eds. Birthweight distribution: an indicator of social development; Report from a SAREC/ WHO Workshop - Uppsala, Swedish Agency for Research Cooperatio. Developing Countries, 1978, p. 9-15.

16. KOIFMAN, S. Bajo peso al nascer y estructura social en Méxica. Xochimilco, Universidad Autónoma Metropolitana, 1977. 112p. Tesis de (Maestria).

17. INSTITUTO BRASILEIRO DE GEOGRAFIA E ESTATISTICA. Censo Detnográfico - 1980. Município de Ribeirão Preto, 31 p. (Mimeo), 1980.

18. BARUFFI, I.; MARTINEZ, A. R.; BALDOCHI, J. Assistência obstétrica no Munić́pio de Ribeiráo Preto (SP) nos anos de 1956 a 1962. Materm. Infanc. (S. Paulo), 24: $117-23,1965$.

19. CAR VALHEIRO, C. D. G. Estudo de mortalidade perinatal em Ribeiräo Preto. Ribeirão Preto, Universidade de São Paulo, Departamento de Higiene e Medicina Preventiva, 1970. 90p. Tese de (Doutoramento).

20. TERUEL, J. R. Mortalidade por diarréia e desnutrição na infância. Ribeiráo Preto, Universidade de Sāo Paulo 1971. Tese de Livre-Docência.

21. PUFFER, R. R. \& SERRANO, C. V. Características de la mortalidad en la niñez. Washington, OPS, 1973. 490p. (Publicación Científica n: 262).

22. CARVALHEIRO, C. D. G. Estudo de algumas varífveis associadas à população feminina em idade fértil - Ribeirão Preto. Ribeirão Preto, Universidade de São Paulo, 1975. Tese de Livre-Docência.

Cadernos de Saúde Pública, RJ, 5 (4): 376-387, out/dez, 1989. 
23. BARBIERI, M. A. Saúde materno-infantil e classe social: alguns aspectos do perfodo perinatal da mảe e do recémrnascido. Ribeirāo Preto, Universidade de São Paulo, 1985. Tese de Livre-Docência.

24. GOMES. U. A. Aspectos epidemiologicos das perdas fetais em R B̈birāo Preto. Ribeirão Preto, Universidad de São Paub, 1979. Tese de Livre-Docência.

25. ROSADO, M. L. C. Estudo do pertmetro craniano $\mathrm{em}$ recém-nascidos na regiăo de Ribeiräo Preto: correlaçāo com dados antropométricos das crianças e fatores biológicos e sociais matemos. Ribeirāo Preto, Universidade de Säo Paulo, 1987. Tese de Doutoramento.

26. ALMEIDA, L. E. A. Mortalidade infantil em R Rbeiråo Preto. Estudo da coorte nascida entre maio de 1978 e maio de 1979. Análise de algumas variáveis sociais e biologicas. Ribeirāo Preto, Universidade de Sāo Paulo, 1988. Dissertaçäo de Mestrado.

27. BARBIERI, M. A. Estudo longitudinal do desenvolvimento físico de crianças de um a dois anos de vida, nascidas vivas com "baixo peso" no Hospital das Cllnicas da Faculdade de Medicina de Ribeiräo Preto da USP. Ribeiräo Preto, Universidade de São Paulo, 1975. Tese de Doutoramento.

28. BARROS FILHO. A. A. Influência de algumas varióveis no peso de recém-nascidos no Hospital das Cltnicas de Ribeiráo Preto. Ribeiräo Preto, Universidade de Säo Paulo, 1976. Dissertagäo de Mestrado.

29. TERUEL, J. R.; GOMES, U. A.; NOGUEIRA, J. L. Investigoção interamericana de mortalidade na infincia; peso ao nascer na regī̄o de Ribeirão Preto, São Paulo, Brasil. In: Investigacăo de mortalidade na infancia no Brasil: descobertas e atividades. Washington, OPS, 1977. p. 24-9. (Publicação Científica, 343).

30. CARVALHEIRO, J. R. Levantamento de condicöes de saúde por entrevistas domiciliárias. Ribeiráo Preto, Universidade de S5̆ Paulo, 1975. Tese de Livre-Docéncia.

31. SINGER, P. I. Dominagio e desigualdade: estrutura de clase e repartiçáo da renda no Brasil. Rio de Janeiro, Paz e Terra, 1981. 185p.

32. POULANTZAS, N. A. As claves socials no capitaliono de hoje. Rio de Janeiro, Zahar, 1978, 368p. 